\title{
BRITISH OR AMERICAN? IRANIAN EFL LEARNERS' PERCEPTIONS TOWARD ENGLISH ACCENTS: EXPLORING POSSIBLE RELATIONSHIPS
}

\author{
Hiwa Weisi, hiwaweisi@gmail.com, Razi University, Kermanshah, Iran \\ Ali Raygan, Razi University, Kermanshah, Iran \\ Fatemeh Bakhtiari, Razi University, Kermanshah, Iran
}

\begin{abstract}
Native English accents (British and American) are known as highly favored and accepted varieties compared to other existing accents in English as foreign language (EFL) context. Notwithstanding the research accomplished on EFL learners' attitudes toward either of the accents (British or American), studies are still scant regarding the investigation of their perspectives in detail toward one of the accents specifically within the context of Iran. The aim of this study is to examine the Iranian EFL learners' attitudes toward the two major known English accents (British and American. Additionally, the study highlights the major factors contributing to the learners' preferences toward either of the accents (British or American). To that aim, a developed and validated questionnaire was distributed among $108 \mathrm{EFL}$ learners selected from two of the major EFL contexts (universities and private institutes). The results indicated that the majority of the learners preferred American over British English accent. Besides, factor analysis revealed that American English exposure, lack of guidance, and lack of reinforcement toward British accent were among the mentioned factors accepted by learners for their preference of American. Finally, the study concludes with interpretations regarding the learners' decision making issues in either of the two major accents, and recommendations are provided for revisiting the EFL learners' attitudes and insights toward native English accents.
\end{abstract}

Key words: British, American, Accent Preference, Iranian Context, EFL Learners.

\section{INTRODUCTION}

In the field of second language acquisition, English as a lingua franca, being referred to as English among speakers with different first languages (Seidlhofer, 2005), has been the subject to most researches during recent years and has effected English language learners' attitudes toward nativeness. English as a lingua franca, as Ferguson (2012) mentions, represents a new viewpoint through which English can be viewed. It is appreciated because of so many reasons among English as foreign language users. For example, raising the awareness to the use of English in communication (Jenkins, 2006), enabling communication across linguistic and geographic boundaries (Seidlhofer, 2009), and bringing speakers a sense of comfort and 


\section{Iranian EFL Learners' Perceptions}

advantage while communicating (House, 2012) are all mentioned as critical factors leading to the ELF (English as a lingua franca) preference by the users. However, although it substantially believes in no communicational context to be culturally neutral as far as all communications involve participants, settings, purposes, and linguistic features (Baker, 2015), the acquisition of native-like English is still prioritized as an ultimate goal in English education (Choi, 2015).

To date, research has found that native English accent is preferred by a large number of the learners, and it is being more desirable as a learning goal (Timmis, 2002). This is because native patterns are considered more prestigious (Lindemann, 2005), and clearer and more understandable than non-native patterns of speech (Jenkins, 2005). Additionally, intolerance toward non-native accents of English (Fayer \& Krasinski, 1987), and the relative familiarity with native accents in comparison to non-native ones (Gill, 1994), makes learners create a preference towards native accents and give lower ratings to the foreign sounding accents. Due to the preferences toward native English accents (as mentioned above), EFL learners have preferred learning English within the norms of either British, or American English due to several reasons such as the ease of access to the native speakers (Moyer, 2007), being considered as more prestigious and more correct compared to the non-native ones (Butler, 2007), and more recently the element of globalization of the mass media (Edwards, 2016), were among the factors highlighted by the previous researches.

There have been a number studies supporting the Iranian EFL teachers and learners' preferences toward native varieties in English specifically for American English (Rajablon \& Shirvan, 2017; Monfared \& Khatib, 2018), and the factors like American status, lack of knowledge about the situation of English around the world, and alike, has been the highlighted issues for the learners' preferences toward American English accent. However, there has been a dearth of information about investigating learners who prefer the British rather than the American English accent, and also about factors supporting their preferences within the EFL context in Iran. The current study attempts to fill the mentioned gap by highlighting the issues that the learners' face when they prefer British English accent over American. Additionally, the difficulty of interpreting the attitudes toward native accents (Garrett, 2010) highlights the need for more meticulous research considering the factors contributing to the learners' attitudes toward major native accents (British or American), and this paucity is taken into consideration by addressing the most prominent factors leading the learners' attention toward selecting either of the major accents (British or American).

Therefore, the foci of the current study are twofold. First, the study focuses on the Iranian EFL learners' attitudes toward the major known accents (British and American) within the two major EFL contexts (Universities and institutes) within Kermanshah region. Second, it highlights the major factors contributing to the learners' preferences toward either of the accents (British or American) in the west of Iran.

10 | IJET| Volume. 8, Issue 2. June 2019 


\section{LITERATURE REVIEW}

\section{a. Learner Preferences}

Considering the issue of preference among native accents as a primary concept, and the influential factors determining attitudes toward native English accents (American or British) as the second challenging issue in EFL learning context, several empirical studies have addressed the issues by probing the EFL learners' native accent preferences from different perspectives.

Focusing on the former issue, Tokumoto and Shibata (2011) uncovered the fact that Japanese and Korean EFL learners disapproved their own varieties in speaking English and had a positive estimation of their preferences toward the standard varieties of English within the educational situations. More confidentially, the results of the language attitude test on a group of language learners in Austria totally confirmed the learners' similar positive attitudes toward native accents, and witnessed student' negative attitudes toward their own non-native speaking accents (Puffer, Kaltenboeck, \&Smit, 2003).

In addition to comprehensive research on learners' positive attitudes toward native accents, a number of other studies have focused on comparing British, American and other English accents (Scales, Wennerstrom, Richard \& Wu, 2006; Ladegaard, \& Sachdev, 2006; Xu, Wang, \& Case, 2010). The aim of the mentioned studies was to find whether there is a difference in the extent to which learners prefer one of the native accents over the others. On the other hand, studies in this phase focused on learners' priorities in case of quality or social acceptance of different accents. The results of the analyses through recorded speeches with both native and non-native accents from authentic sources (the people who were the speakers of that accent) and playing them to the learners revealed that they had a positive attitude toward speaking English with a native accent. Moreover, the comparisons uncovered the fact that learners carried a positive attitude toward American accent and preferred it more than the other available accents. Furthermore, learners' accents preferences (in these cases American English accent) was assumed to have a positive relationship with its easiness in understanding (Scales et al., 2006), the solidarity and attractiveness of culture behind the accent (Ladegaard \& Sachdev, 2006), and the amount of exposure and usage of materials which are based on native models of accent (Xu, Wang, \& Case, 2010).

However, considering British as another available variety which is as equally known and important as the American English accent, none of the previous researches up to date have accurately focused on those who prefer British to American or to other English accents and also features that motivate learners into selecting this English accent. This study therefore aims to fill the gap by focusing on the ideas of the British accent proponents just like their American counterparts. 


\section{b. Factors Contributing to Learner Preferences}

Many of the previous research have highlighted the major factors leading to the learners' preferences toward either of the accents (British or American). Thompson (1991) reported that samples provided for judgment about an accent as well as the linguistic experience of the listeners toward that accent can affect learners' perceptions toward that accent. In the study conducted by Bresnahan, Ohashi, Nebashi, Liu, and Shearman (2002), the analyzed results ensured the importance of speaker identity as a predominant factor in accent preferences among the EFL learners. On the other hand the findings signified that; "Those exhibiting strong ethnic identity had more positive attitudes toward American English and showed a strong preference for American English compared to foreign accents" (Bresnahan et al, 2002, p.182). In addition, the study highlighted the direct relationship between identity and accent preference in that those with stronger identities believed in having more intelligible accents like American. Moreover, considering EFL learners, the study by Bresnahan et al. (2002) marked the link the element of intelligibility in a particular accent, the learners' positive attitudes toward that accent. On the other hand when intelligibility is low, the learners' negative attitudes toward the accents are more tangible because of the difficulties they receive in understanding teachers' assistance. Additionally, Carrie (2017) in his research highlighted the element of accent prestige as a pre determiner in accent preference by the learners and confirmed that learners often consider British accent as high status and prestige. Moreover, he alleged the main factor Behind American English to be its greater solidarity. Finally, as Kung and Wang (2018) mention, several sociocultural factors such as textbooks, TV series, teachers, peers, and learning context influence the learners' attitudes toward accents.

However, Within the Iranian EFL learning context, research is quite rare in that studies, as mentioned before, only tap limited and surface series of factors influencing the learners' attitudes toward either of the accents (British or American). Also the cases previous researches have mostly focused were mostly American English accent proponents and those who preferred British were mostly failed to be studied. This study therefore addresses the observed paucity by targeting the factors contributing to the selection of either of the accents (British or American) in a more comprehensive manner.

Above that, a more meticulous and detailed factor analysis is demanded in that patterns of misidentification have been captured in the previous literature. In the study by Scales, Wennerstrom, Richard, and $\mathrm{Wu}$ (2012), the mismatch between learners' own goals and their disabilities in identifying the accents has been highlighted. Considering the element of misidentification, the study revealed that more than half of the learners had their goal toward sounding like a native speaker, but only $29 \%$ of them were able to identify the American English accent itself. Considering the element of awareness of the learners, despite the higher position and socially accepted features of American English accent and the fact that it was favored by the EFL learners, most of the learners missed to identify the accent because of their

12 | IJET | Volume. 8, Issue 2. June 2019 
lack of awareness in identifying the accent by its features (Carrie \& McKenzie, 2018). Due to the fact that learners have had positive attitudes toward the native accents (e.g. American English accent) even without recognizing the accents by their names and features, there may be many other factors contributing to the learners' preferences toward these accents which seek for further clarification. Consequently, this study aims at investigating the Iranian EFL learners' attitudes toward two of the major English accents (British or American). The study then aims at highlighting the factors contribute to the learners` preferences toward either of the accents.

\section{RESEARCH QUESTIONS}

Due to the mentioned drawbacks of the previous researches, the current study aims at investigating the Iranian EFL learners' attitudes toward the major native English accents (British and American). Additionally, the study highlights the factors contributing to the learners' preferences toward either of the accents (British or American). Therefore, the following research questions are formulated:

1. What are the Iranian EFL learners' attitudes toward the British or American English accent?

2. What are the factors contributing to the Iranian EFL learners` preferences toward either of the English accents (British or American)?

\section{METHOD}

\subsection{Participants}

Two major groups of Iranian language learners (public universities and private institutes) participated in this study through a stratified random sampling procedure. A total number of 108 English language learners of both genders (50 male and 58 female) were recruited to participate in the study from two of the universities (Razi University and Azad University), and three private institutes within Kermanshah region. The field of study for all the university students was English literature and all the private institute learners had their English language learning courses. The participants' age ranged from 10 to 27 and they had different levels (beginner, intermediate, and advanced). All of the participants' mother tongue was either Persian or Kurdish and their second language learning experience ranged from less than a year to 16 years. 
Iranian EFL Learners' Perceptions

Table 3.1

Participants' demographic characteristics, frequency, and percentage

Demographic characteristics

Frequency/percentage

Gender

- Male

$50 / 46.3 \%$

- Female

$58 / 53.7 \%$

Experience (years)

- $1-5$

$28 / 25.9 \%$

- 6-10

$60 / 55.6 \%$

- 11-16

$8 / 7.4 \%$

Age

- $10-15$

$22 / 20.4 \%$

- 16-21

$40 / 37 \%$

- 22-27

$31 / 28.7 \%$

\subsection{Instruments}

This study developed a questionnaire though interviewing 100 of the English language learners studying English in Universities and private institutes of the same region. The interviews were conducted in Persian to allow the interviewees to express their opinions freely. The themes were then extracted and transcribed to be utilized as the questionnaire items. As the first step, initial piloting was conducted so as to reduce the large list of questions to the intended final number. The items were then administered by hand among 50 EFL learners of Razi University, Azad University and two of the private institutes in Kermanshah province for final piloting. The final version of the questionnaire was put together based on the feedbacks received from the pilot group. In order to measure the internal consistency of the modified questionnaire, Cronbach's Alpha coefficient was utilized. Bartlett's test of sphericity and the Kaiser-Meyer-Olkin (KMO) were then utilized to measure the inter-correlations among the items in the questionnaire to assure the suitability of running factor analysis. Table 3.2 provides the values for the KMO test respectively.

14 | IJET| Volume. 8, Issue 2. June 2019 


\section{Table 3.2}

\section{KMO and Bartlett's Test}

\begin{tabular}{ll}
\hline Kaiser-Mayer-Olkin Measure of Sampling adequacy & .640
\end{tabular}

\begin{tabular}{lll}
\hline Bartlett`s Test of Sphericity & Appox Chi-Square & 221.926
\end{tabular}

df 55

Sig.

.000

The final version of the questionnaire included 20 Likert scale items. The participants were asked to rate each statement by posing their level of agreement through choosing one of the choices: 1= Strongly Agree, 2= Agree, 3= Undecided, 4= Disagree, 5= Strongly Disagree. The questionnaire consisted of three main sections. The first section was designed to gain the background information of the participants. The second section of the questionnaire, including 9 items, was devised in a way to address our first research question regarding the attitudes of EFL learners toward British or American English accent. The last part of the questionnaire, which was focusing on the second research question, included 11 items addressing the related factors contributing to their attitudes toward either of the accents (British or American English).

\subsection{Data Collection and Analysis Procedure}

The finalized version of the questionnaire was distributed among 120 of EFL learners, from the above mentioned contexts, in the forms of hard copies and email attachments. Data collection process of this study lasted for three months due to the fact that the respondents were given enough time to respond to the items free of any limitations. The standards for the length of the questionnaire were properly addressed by administering a five page survey which took around 25 minutes to be completed. The respondents were assured that their answers would be used for no other reasons except for research purposes and would be kept strictly confidential.

SPSS (version 21) was utilized for the quantitative data analysis of the study. Included in the analysis were the frequencies, rates, and percentages, as well as Central tendency measures (mean, mode, and median), and variability measures (range and standard deviations). Mentioning the fact that the normality tests' values were lower than the minimum acceptable range of .05 , confirming the normality of distribution was negative and the data were analyzed using the non-parametric tests. Considering the first section of the questionnaire, Spearman`s rho correlation coefficient was conducted to find out the correlations between the items, and the 
second research question regarding the factors contributing to the learners' attitudes toward either of the accents, factor analysis was utilized.

\section{RESULT}

\subsection{First research question: What are the Iranian EFL learners`attitudes toward British or American English accent?}

In order to address the first research question regarding the EFL learners`attitudes toward British or American English accent, their ratings for item number two (2) were utilized. As shown in table 1.3 , it can be claimed more than $60 \%$ of the participants has their negative attitudes toward British English accent.

\section{Table 4.1}

Descriptive statistics, attitudes toward British English accent

\section{Statement}

$\mathrm{F} / \%$

(2) I love British Accent

\begin{tabular}{ccccc} 
SA & A & UD & D & SD \\
\hline 4.6 & 8.3 & 25.0 & 36.1 & 25.9 \\
\hline
\end{tabular}

In addition to the fact that the majority of the participants revealed positive attitudes toward American English accent, Spearman's rho correlation coefficient, which is the nonparametric version of the Pearson product-moment correlation, was conducted to find out if there is any relationship between the EFL learners' age and their attitudes toward British or American English accent. Based on the results of the study, there happened to be a moderate, but significant positive relationship between the EFL learners age and their attitudes toward American teachers and their accents $\left(r_{s}=0.40, p<0.01\right)$. This indicates the fact that the learners, whose age ranged higher, preferred the American English accent rather than British accent.

Furthermore, the results from the test showed that there is a strong and significant relationship between learners' positive attitudes toward American English (\#3) and their interests toward American accent tone of speech $\left(r_{s}=0.60, p<0.01\right)$ as being more pleasant to them than that of British (\#5). Consequently, a medium but significant relationship was observed between those EFL learners` attitudes toward American teachers (\#1) and their tone of speech (\#5) in their learning context $\left(\mathrm{r}_{\mathrm{s}}=0.41, \mathrm{p}<0.01\right)$.

Finally, considering the results of the spearman correlation revealed a medium but significant relationship between the EFL learners` positive attitudes toward British accent (\#2), and their beliefs toward British fluency $(\# 6)\left(r_{s}=0.44, p<0.01\right)$. On the other hand, the results indicate a medium but significant relationship between the learners`Attitude toward American

16 | IJET| Volume. 8, Issue 2. June 2019 
English (\#1) and the pleasantness of American speakers` tone of speech (\#5) $\left(\mathrm{r}_{\mathrm{s}}=0.41, \mathrm{p}<\right.$ $0.01)$.

\subsection{Second research question: What factors contribute to the learners' attitudes toward either of the accents (British or American)?}

As explained previously, the second research question regarding the factors contributes to the learners' attitudes toward British or American English was addressed through conducting a factor analysis. The aim for using factor analysis was to reduce the number of defendant variables into more comprehensive underlying variables in order to determine and predict the learners`attitudes toward each of the accents. Besides, this technique is based upon the fact that the correlations among the items are the representations for the commonalities between them. The suitability of running factor analysis was ensured through utilizing Bartlett's test of sphericity and the Kaiser-Meyer-Olkin (KMO). KMO index for the present study was .64 which implies the appropriate index for conducting a factor analysis. In order to determine the number of underlying factors, the screen plot (Figure 4.1) was inspected.

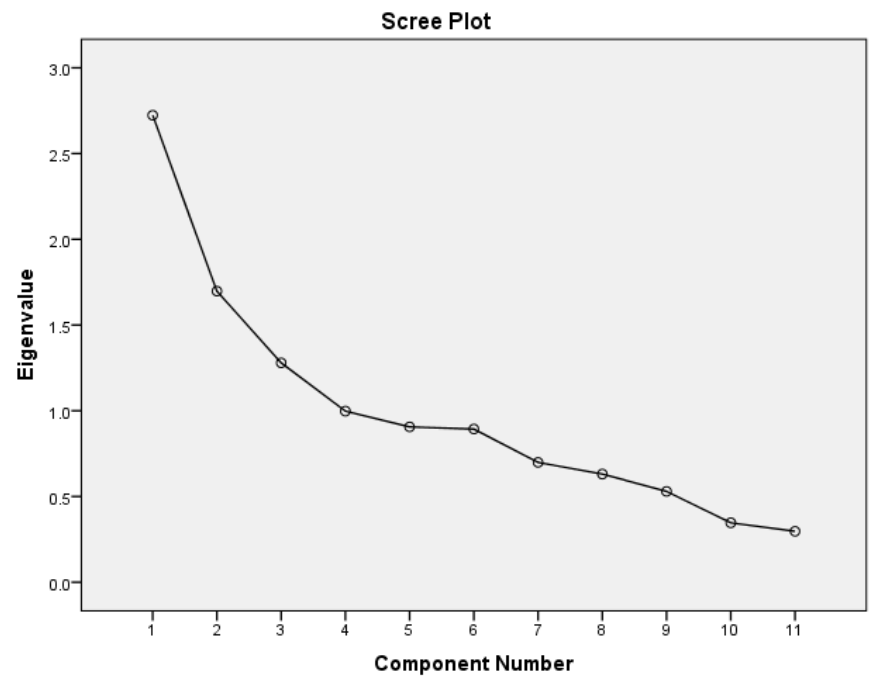

As shown in figure 4.1, three main items were loaded as the most important predictors of the Iranian EFL learners' attitudes toward the English accents. On the other hand, the 11 items utilized in the second section of the questionnaire were summarized into 3 main factors. Additionally, in order to determine the underlying items for each of the factors, the coefficient for each of the items of the questionnaire were obtained as shown in table 4.2.

\section{Table 4.2}

Component matrix 
Iranian EFL Learners' Perceptions

\begin{tabular}{cccc}
\cline { 2 - 4 } & Factor 1 & Factor 2 & Factor 3 \\
\hline Item 1 & -.154 & .489 & .526 \\
Item 2 & .572 & .140 & .290 \\
Item 3 & .034 & .215 & .526 \\
Item 4 & .231 & .218 & .393 \\
Item 5 & .139 & .547 & .033 \\
Item 6 & -.447 & .702 & -.249 \\
Item 7 & -.281 & .646 & -.454 \\
Item 8 & .722 & .294 & .072 \\
Item 9 & .782 & .184 & -.223 \\
Item 10 & .612 & .090 & -.390 \\
Item 11 & .716 & -.076 & -.105 \\
\hline
\end{tabular}

As illustrated in table 4. , the first factor is a common factor among items 2, 8, 9, 10, and 11 as far as their loadings are much higher than those of the other items. Due to the commonalities among the mentioned items, this factor therefore can be identified as American English exposure. Factor number two is common among items number 5, 6, and 7 due to the fact that their loadings are higher than the rest of the items. Considering the point that the mentioned items focus of the role of the teachers as the learners' guides toward either of the accents (British or American English), the second factor dominating them can be identified as lack of guidance. The last factor is a common one among items 1, 3, and 4 since all three items resemble each other in terms of their content and their loadings. So the third factor which carries the content of the mentioned items can be identified as lack of reinforcement toward British accent. Moreover, as shown in figure 4.1 American English exposure can be enumerated as the most important factor which contributes to the learners' attitudes toward American English accent. The factor explains the students' ease of access to the American books, sources, teachers, and the American native speakers more than those who preferred British English accent. The second important factor elaborates on the guidance on the side of teachers which leaves the students demotivated most of the time to choose British rather than American English accent, and the last factor contributing to the students' attitudes toward American English accent and ignoring the British accent is that of reinforcement toward British accent within the environmental context of Iran.

\section{DISCUSSION}

The current study concentrated on providing a number of insights and broader views into the EFL learners` attitudes toward two of the major accents in English language teaching, as well as having a greater look at the factors contributing to the learners' attitudes and preferences toward either of the accents (British or American). The first section of the study,

18 | IJET| Volume. 8, Issue 2. June 2019 
targeting the Iranian EFL learners' attitudes toward either British or American accent indicated that, considering the pleasantness of the tone of speech, the majority of the students (62\%) had their positive attitudes toward American as a dominant accent. However, there were still some of the students (12.9\%) who preferred the British accent because of the fluency they experienced as they were speaking. Confirming the previous researches, the analysis of the third item from the established questionnaire (\#3) revealed that $25 \%$ of the included participants remained undecided in terms of their attitudes toward either of the accents and as previous studies suggest, it can be attributed to difficulties or no differences in making decisions between the two accents (Buckingham, 2014).

The current study also aimed at investigating the factors contributing to the learners' preferences toward each one of the major accents in Iranian EFL context by having a more meticulous look at those factors in both parties (British or American accent proponents). The study highlighted three main factors contributing to the students' attitudes toward American English accent. The first factor, American English exposure, expressed the greater use of the facilities associated with American English accent and revealed that those who prefer the American English accent over British are exposed more to the American facilities. This confirms both Kung and Wang (2018) and Ahn's (2011) study considering the fact that the proponents of this accent have been exposed to American English accents more than the other varieties and that they rarely experience listening to other varieties. Students` lack of exposure toward other varieties of English is also confirmed by Billiris (2011). Therefore, it can be inferred that the main reason for the majority of cases to choose American English accent is not what they think of America and American residency (American status), but it is the dominant influence of the American media, as Edwards (2016) mentions, which leads them to choose American English accent. The second identified factor, lack of guidance, targeted the teachers' assistance on students who wanted to choose from the variety of the accents. The findings are also supported by Chang (2013) as he calls on teachers as facilitators for students while choosing accents in EFL context. The last element which is not mentioned as such in the literature is referred to as lack of reinforcement toward British accent. As mentioned by Phothongsunan (2017), the main reason for the students' positive attitudes toward any of the native accents is the motivation they receive from their teachers. It can also be interpreted that holding a positive attitude toward British accent as a major English accent is heavily dependent of how the students are motivated enough to make up their minds toward British accent.

\section{CONCLUSION AND IMPLICATIONS}

The study evaluated the Iranian EFL learners' attitudes toward British or American English and considered the factors contributing to the participants` preferences toward either of the accents. The results for the first research question of the study targeting the learners' attitudes toward British or American English showed that the majority of the language learners 


\section{Iranian EFL Learners' Perceptions}

(over 60\%) preferred American English accent. The results also revealed a significant positive relationship between the learners' attitudes toward American English accent and the American tone of speech. Additionally, the relationship between the learners' age and the positivity of their attitude toward American English accent was significant. On the other hand, there was a significant positive relationship between the learners`attitudes toward British accent and British fluency as a prior element. The second research question addressing the factors influencing the learners' attitudes toward either of the accents (British or American) revealed that American English exposure, Lack of guidance from the teachers, and lack of reinforcement toward British English accent were among the major factors identified by the learners.

Due to the fact that the previous literature highlights the boldness of American English accent and in some cases the British English accent within the Iranian EFL context, this study hopes to offer a more informed point of view toward exposure into the accents in that the learners may need to be exposed to the other varieties of English accent that are equally known as the two highlighted ones (British or American). Considering the idea of world Englishes mentioned by Kachru and Smith (2009), and Kachru (1985) model regarding spreading English in three circles, as Iran is among the outer circle communities of EFL teaching and learning, it might be pretty mouthful not only on the varieties on inner circle (British or American), but also on the existing varieties within the expanding circle. A novel, yet unsurprising, finding which is highlighted in this study is the lack of exposure and guidance toward other varieties of English which denotes the fact that learners within the Iranian EFL context may be interested in other varieties of English other than British or American English accent if they are exposed and guided toward those accents accurately.

\section{REFERENCES}

Ahn, K. (2011). Conceptualization of American English native speaker norms: a case study of an English language classroom in South Korea. Asia Pacific Education Review, 12(4), 691-702. doi: 10.1007/s12564-011-9169-6.

Baker, W. (2015). Culture and complexity through English as a lingua franca: rethinking competences and pedagogy in ELT. Journal of English As A Lingua Franca, 4(1). doi: 10.1515/jelf-2015-0005.

Bresnahan, M., Ohashi, R., Nebashi, R., Liu, W., \& Morinaga Shearman, S. (2002). Attitudinal and affective response toward accented English. Language \& Communication, 22(2), 171-185. doi: 10.1016/s0271-5309(01)00025-8.

Buckingham, L. (2014). Recognising English accents in the community: Omani students' accent preferences and perceptions of nativeness. Journal of Multilingual and Multicultural Development, 36(2), 182-197. doi: 10.1080/01434632.2014.909443.

Butler, Y. (2007). How Are Nonnative-English-Speaking Teachers Perceived by Young Learners?. TESOL Quarterly, 41(4), 731-755. doi: 10.1002/j.1545-7249.2007.tb00101.x

Carrie, E. (2016). 'British is professional, American is urban': attitudes towards English reference accents in Spain. International Journal of Applied Linguistics, 27(2), 427-447. doi: $10.1111 /$ ijal.12139.

20 | IJET| Volume. 8, Issue 2. June 2019 
Carrie, E., \& McKenzie, R. (2018). American or British? L2 speakers' recognition and evaluations of accent features in English. Journal of Multilingual and Multicultural Development, 39(4), 313-328. doi: 10.1080/01434632.2017.1389946.

Billiris, C. (2012). A Study into the Accent Attitude and Preferences of Korean EFL Students. English Language Teaching, 23(4), 1-23. doi: 10.17936/pkelt.2012.23.4.001

Chang, C. (2013). Exploring the beliefs of native and non-native English speaking kindergarten teachers in Taiwan. International Journal of Research Studies In Language Learning, 2(5). doi: 10.5861/ijrsll.2012.171.

Choi, L. (2015). Revisiting the issue of native speakerism: 'I don't want to speak like a native speaker of English'. Language and Education, 30(1), 72-85. doi: 10.1080/09500782.2015.1089887.

Fayer, J., \& Krasinski, E. (1987). Native and Nonnative Judgments of Intelligibility and Irritation. Language Learning, 37(3), 313-326. doi: 10.1111/j.14671770.1987.tb00573.x.

Ferguson, G. (2012). Barbara Seidlhofer: Understanding English as a Lingua Franca. Oxford University Press, 2011. Applied Linguistics, 33(4), 463-465. doi: 10.1093/applin/ams035

Garrett, P. (2010). Attitudes to language [e-book]. Retrieved from https://books.google.com Gill, M. (1994). Accent and stereotypes: Their effect on perceptions of teachers and lecture comprehension. Journal of Applied Communication Research, 22(4), 348-361. doi: 10.1080/00909889409365409

Hansen Edwards, J. (2016). Accent preferences and the use of American English features in Hong Kong: a preliminary study. Asian Englishes, 18(3), 197-215. doi: 10.1080/13488678.2016.1225482

House, J. (2012). English as a lingua franca and linguistic diversity. Journal of English as a Lingua Franca, 1(1). doi: 10.1515/jelf-2012-0008

Jenkins, J. (2005). Implementing an International Approach to English Pronunciation: The Role of Teacher Attitudes and Identity. TESOL Quarterly, 39(3), 535. doi: 10.2307/3588493

Jenkins, J. (2006). Current Perspectives on Teaching World Englishes and English as a Lingua Franca. TESOL Quarterly, 40(1), 157. doi: 10.2307/40264515

Kachru, B. (1990). World Englishes and applied linguistics. World Englishes, 9(1), 3-20. doi: 10.1111/j.1467-971x.1990.tb00683.x

Kachru, Y., \& SMITH, L. (2009). The Karmic cycle of world Englishes: some futuristic constructs. World Englishes, 28(1), 1-14. doi: 10.1111/j.1467-971x.2008.01566.x

Kung, F., \& Wang, X. (2018). Exploring EFL Learners' Accent Preferences for Effective ELF Communication. RELC Journal, 003368821876530. doi: 10.1177/0033688218765306

Ladegaard, H., \& Sachdev, I. (2006). 'I Like the Americans... But I Certainly Don't Aim for an American Accent': Language Attitudes, Vitality and Foreign Language Learning in Denmark. Journal of Multilingual and Multicultural Development, 27(2), 91-108. doi: 10.1080/01434630608668542.

Lindemann, S. (2005). Who speaks "broken English"? US undergraduates' perceptions of nonnative English1. International Journal of Applied Linguistics, 15(2), 187-212. doi: 10.1111/j.1473-4192.2005.00087.x

Monfared, A., \& Khatib, M. (2018). English or Englishes? Outer and Expanding Circle Teachers' Awareness of and Attitudes towards their Own Variants of English in 


\section{Iranian EFL Learners' Perceptions}

ESL/EFL Teaching Contexts. Australian Journal of Teacher Education, 43(2), 56-75. doi: $10.14221 /$ ajte.2018v43n2.4

Moyer, A. (2007). Do Language Attitudes Determine Accent? A Study of Bilinguals in the USA. Journal of Multilingual and Multicultural Development, 28(6), 502-518. doi: 10.2167/jmmd514.0

Phothongsunan, S. (2017). Perceiving Native English Speaking Teachers: EFL University Students' Perspectives. Arab World English Journal, 8(4), 259-267. doi: 10.24093/awej/vol8no4.17

Rajablou, F., \& Shirvan, M. (2017). Iranian English Language Learners' Attitude towards their Accent in English Language: An Ecological Approach. Englishes In Practice, 4(1), 130. doi: 10.1515/eip-2017-0001

Scales, J., Wennerstrom, A., Richard, D., \& Wu, S. (2006). Language Learners' Perceptions of Accent. TESOL Quarterly, 40(4), 715. doi: 10.2307/40264305

Seidlhofer, B. (2005). English as a lingua franca. ELT Journal, 59(4), 339-341. doi: 10.1093/elt/cci064

Seidlhofer, B. (2009). Common ground and different realities: world Englishes and English as a lingua franca. World Englishes, 28(2), 236-245. doi: 10.1111/j.1467-971x.2009.01592.x

Thompson, I. (1991). Foreign Accents Revisited: The English Pronunciation of Russian Immigrants*. Language Learning, 41(2), 177-204. doi: 10.1111/j.14671770.1991.tb00683.x

Timmis, I. (2002). Native-speaker norms and International English: a classroom view. ELT Journal, 56(3), 240-249. doi: 10.1093/elt/56.3.240

Tokumoto, M., \& Shibata, M. (2011). Asian varieties of English: Attitudes towards pronunciation. World Englishes, 30(3), 392-408. doi: 10.1111/j.1467971x.2011.01710.X

Xu, W., Wang, Y., \& Case, R. (2010). Chinese attitudes towards varieties of English: a preOlympic examination. Language Awareness, 19(4), 249-260. doi: 10.1080/09658416.2010.508528. 